\title{
Synthesis and reactivity of (N2P2)Ni complexes stabilized by a novel diphosphonite pyridinophane ligand
}

\author{
Kei Fuchigami," Michael B. Watson," Giang N. Tran, ${ }^{\dagger}$ Nigam P. Rath, ${ }^{\neq}$and Liviu M. Mirica*,† \\ ${ }^{\dagger}$ Department of Chemistry, University of Illinois at Urbana-Champaign, 600 S. Mathews Avenue, Urbana, Illinois 61801, United States, \\ \# Department of Chemistry, Washington University, One Brookings Drive, St. Louis, Missouri 63130-4899 and ${ }^{\ddagger}$ Department of Chem- \\ istry and Biochemistry, University of Missouri-St. Louis, One University Boulevard, St. Louis, Missouri 63121-4400. \\ *mirica@illinois.edu \\ Nickel, C-C bond formation, $\mathrm{Ni}(\mathrm{I})$ and $\mathrm{Ni}(\mathrm{II})$ complexes, ligand design
}

\begin{abstract}
A series of (N2P2)Ni ${ }^{I I}$ complexes (N2P2 = P,P'ditertbutyl-2,11-diphosphonito[3.3](2,6)pyridinophane) stabilized by a modified tetradentate pyridinophane ligand containing two phosphonite groups were synthesized and characterized. Cyclic voltammetry (CV) studies revealed the accessibility of the $\mathrm{Ni}^{\mathrm{I}}$ oxidation state at moderate redox potentials for these $\mathrm{NiII}$ complexes. In situ EPR, low-temperature UV-vis, and electrochemical studies were employed to detect the formation of $\mathrm{Ni}^{\mathrm{I}}$ species during the reduction of $\mathrm{Ni}^{\mathrm{II}}$ precursors. Furthermore, the $[(\mathrm{N} 2 \mathrm{P} 2) \mathrm{Ni}(\mathrm{CNtBu})]\left(\mathrm{SbF}_{6}\right)$ complex was isolated upon reduction of the $\mathrm{Ni}^{\mathrm{II}}$ precursor with 1 equiv of $\mathrm{CoCp}_{2}$, and was characterized by EPR and X-ray photoelectron spectroscopy (XPS). Finally, the (N2P2) $\mathrm{Ni}^{\mathrm{II}} \mathrm{Br}_{2}$ complex acts as an efficient catalyst for the Kumada cross-coupling of an aryl halide with an aryl or alkyl Grignard, suggesting that the N2P2 ligand can support the various Ni species involved in the catalytic C-C bond formation reactivity.
\end{abstract}

\section{Introduction}

In addition to Pd-catalyzed transformations, Ni-based catalytic systems have recently been developed that can promote Negishi, Kumada, and Suzuki cross-coupling reactions. ${ }^{1-10}$ Contrary to the extensively studied Pd-mediated transformations that employ diamagnetic intermediates, $\mathrm{Ni}$ has been found to undergo both one- and two-electron redox reactions leading to additional reaction pathways. Although there is evidence that $\mathrm{Pd}$ can also undergo similar redox reactions, $\mathrm{Ni}$ has been more commonly accepted to involve the +1 and +3 oxidation states in the aforementioned cross-coupling reactions. ${ }^{11-20}$ The presence of these paramagnetic species has made the characterization of these reactive species more difficult, ${ }^{21-25}$ yet a detailed understanding of these paramagnetic Ni complexes will lead to the development of more efficient and selective catalysts for $\mathrm{Ni}$ mediated cross-coupling reactions.

In the past several years we have reported the isolation and characterization of mononuclear organometallic $\mathrm{Ni}^{\mathrm{III}}$ complexes stabilized by tetradentate ${ }^{\mathrm{R}} \mathrm{N} 4$ ligands ( ${ }^{\mathrm{R}} \mathrm{N} 4=\mathrm{N}, \mathrm{N}^{\prime}$-dialkyl-2,11-diaza[3.3](2,6)pyridinophane, $\mathrm{R}=\mathrm{Me}$, ${ }^{\mathrm{i}} \mathrm{Pr}$, or ${ }^{t} \mathrm{Bu}$ ) as well as its $\mathrm{C}$-donor derivative ${ }^{\mathrm{R}} \mathrm{N} 3 \mathrm{C}$ - ligands $\left(\mathrm{R}={ }^{t} \mathrm{Bu}\right.$, tert-butyl or Np, neopentyl) that can undergo $\mathrm{C}-\mathrm{C}$ and $\mathrm{C}$-heteroatom bond formation reactions. ${ }^{26-36}$ These results suggest that $\mathrm{Ni}{ }^{\mathrm{III}} \mathrm{com}$ plexes are more common than previously anticipated, and thus it prompted us to now target the low-valent $\mathrm{Ni}^{\mathrm{I}}$ species using a slightly modified ligand system. Inspired by the many examples of PONOP-type pincer metal complexes, ${ }^{37-41}$ we have developed the $\mathrm{N}$ - and $\mathrm{P}$ - donor tetradentate ligand N2P2 (N2P2 = $\mathrm{P}, \mathrm{P}^{\prime}$ ditertbutyl-2,11-diphosphonito[3.3](2,6)pyridinophane) and investigated the redox properties and reactivity of its $\mathrm{Ni}$ complexes. Reported herein are the synthesis, characterization, and reactivity studies of a series of (N2P2)Ni complexes, including a rare $\left[(\mathrm{N} 2 \mathrm{P} 2) \mathrm{Ni}^{\mathrm{I}}(\mathrm{CNtBu})\right]\left(\mathrm{SbF}_{6}\right)(6)$ complex. Interestingly, we have also observed that the (N2P2) $\mathrm{Ni}^{\mathrm{II}} \mathrm{Br}_{2}$ (1) complex can catalyze the Kumada cross-coupling of an aryl halide with an aryl or alkyl Grignard, suggesting that the N2P2 ligand can support the various $\mathrm{Ni}$ species that are involved in the catalytic C-C bond formation reactivity.

\section{Experimental Details}

Reagents and Materials. All manipulations were carried out under a nitrogen atmosphere using standard Schlenk and glove box techniques if not indicated otherwise. All reagents for which the synthesis is not given were commercially available from Sigma-Aldrich, Fischer, or Strem and were used as received without further purification. Solvents were purified prior to use by passing through a column of activated alumina using an MBRAUN SPS. Ni(DME)Br 2 (DME = ethylene glycol dimethyl ether) was prepared according to a modified literature procedure. 42

\section{Scheme 1. Synthesis of (N2P2)NiII Complexes}
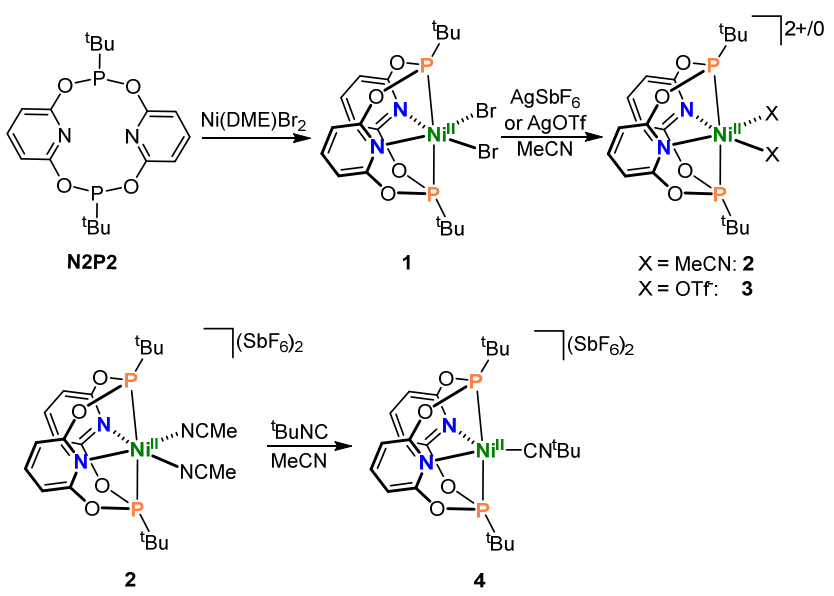

Physical Measurements. ${ }^{1} \mathrm{H}(300.121 \mathrm{MHz})$ NMR spectra were recorded on a Varian Mercury-300 spectrometer. Solution magnetic susceptibility measurements were obtained by the Evans method ${ }^{43}$ using coaxial NMR tubes at 293 K. Diamagnetic 
corrections were applied as previously described. ${ }^{44} \mathrm{UV}$-vis spectra were recorded on a Varian Cary 50 Bio spectrophotometer and are reported as $\lambda_{\max }, \mathrm{nm}\left(\varepsilon, \mathrm{M}^{-1} \mathrm{~cm}^{-1}\right)$. The low temperature UV-vis measurements were performed using a fiber-optic immersion probe (Hellma, pathlength $1 \mathrm{~mm}$ or $10 \mathrm{~mm}$ ). EPR spectra were recorded on a JEOL JES-FA X-band (9.2 GHz) EPR spectrometer at $77 \mathrm{~K}$ or $298 \mathrm{~K}$. EPR spectra simulation and analysis were performed using Bruker WINEPR SimFonia program, version 1.25. ESI-MS experiments were performed using a Thermo FT or Bruker Maxis Q-TOF mass spectrometer with an electrospray ionization source. Elemental analyses were carried out by the Columbia Analytical Services Tucson Laboratory. Cyclic voltammetry experiments were performed with a BASi EC Epsilon electrochemical workstation or a CHI 660D Electrochemical Analyzer.

Electrochemical Measurements. Electrochemical-grade $\mathrm{Bu}_{4} \mathrm{NClO}_{4}$ (Fluka) was used as the supporting electrolyte. Electrochemical measurements were performed in the $\mathrm{N}_{2}$-filled glove box or under a blanket of nitrogen, and the analyzed solutions were deaerated by purging with nitrogen. A glassy carbon disk electrode $(d=1.6 \mathrm{~mm})$ was used as the working electrode, a Pt wire was used as the counter electrode, and a $\mathrm{Ag}$ wire pseudo-reference or a $\mathrm{Ag} / 0.01 \mathrm{M} \mathrm{AgNO}_{3} / \mathrm{MeCN}$ electrode was used as the reference electrode. The non-aqueous reference electrode was calibrated against $\mathrm{Cp}_{2} \mathrm{Fe}(\mathrm{Fc})$. Caution! Perchlorate salts are potentially explosive and should be handled with appropriate care only in small quantities.

Synthesis of N2P2 ligand. 2,6-Dihydroxypyridine hydrochloride (Aldrich, $500 \mathrm{mg}, 3.388 \mathrm{mmol}$ ) and $100 \mathrm{~mL}$ of THF was combined in a schlenk flask equipped with a rubber septum. The solution was precooled. To the above mixture, n-butyl lithium (Aldrich $2.5 \mathrm{M}$ in hexane, $4 \mathrm{~mL}, 10.00 \mathrm{mmol}$ ) was added drop wise while stirring. The reaction mixture was brought to room temperature and stirred for 1.5 hours. After the solution became cloudy, a phosphine solution of p,p-dichloro-tertbutylphosphine (Aldrich 1.0 M in Et $\mathrm{E}_{2} \mathrm{O}, 3.2 \mathrm{~mL}, 3.227 \mathrm{mmol}$ ) in 100 $\mathrm{mL}$ of THF was prepared and added dropwise. The reaction mixture was further stirred for 24 hours. The solvent was then removed under vacuum, leaving an oily yellow solid. The solid was extracted into pentane and filtered. The solution was dried to obtain a white powder. The ${ }^{1} \mathrm{H}$ NMR spectrum in $\mathrm{CDCl}_{3}$ and ESI-MS results show that it is a mixture of N2P2 dimer and the 'N4P4' tetramer. Yield: $488 \mathrm{mg}, 73 \%$. ${ }^{1} \mathrm{H}$ NMR $(300 \mathrm{MHz}$, $\left.\left(\mathrm{CD}_{3}\right)_{2} \mathrm{CO}\right) \delta(\mathrm{ppm}): 1.23(\mathrm{~d}, J=13.1 \mathrm{~Hz}, 18 \mathrm{H}, \mathrm{tBu}), 6.73(\mathrm{~d}, J=$ $\left.7.8 \mathrm{~Hz}, 4 \mathrm{H}, \mathrm{Py} \mathrm{H}_{\text {meta }}\right), 7.81$ (t, $J=7.8 \mathrm{~Hz}, 2 \mathrm{H}$, Py $\left.\mathrm{H}_{\text {para }}\right)$. ESI-MS $(\mathrm{m} / \mathrm{z}): 395.1304$, calculated for [N2P2] $\mathrm{H}^{+}: 395.1272$.

Synthesis of (N2P2)NiBr 2 (1). The complex was prepared under $\mathrm{N}_{2}$. A solution of $\mathrm{Ni}(\mathrm{DME}) \mathrm{Br}_{2}(21.2 \mathrm{mg}, 0.068 \mathrm{mmol})$ was added to a solution of $\mathrm{N} 2 \mathrm{P} 2$ (31mg, $0.079 \mathrm{mmol})$ in DCM. The mixture turned dark red. After stirring for 1 hour, the solution was filtered and concentrated for recrystallization by pentane diffusion. Black crystals formed, and the supernatant was removed. The resulting solid was washed with pentane and dried in vacuo. The product (N2P2) $\mathrm{NiBr}_{2}$ was isolated as a black solid. Yield: $28 \mathrm{mg}, 67 \%$. ${ }^{1} \mathrm{H}$ NMR $\left(\mathrm{CD}_{3} \mathrm{CN}, 300 \mathrm{MHz}\right), \delta(\mathrm{ppm})$ : 1.51 (s, 18H, tBu), 6.79 (d, 8H, Py Hmeta), 7.82 (br, 2H, Py Hpara). Elemental analysis: found, C 34.35, H 4.06 N 4.00\%; calculated $\mathrm{C}_{18} \mathrm{H}_{26} \mathrm{Br}_{2} \mathrm{~N}_{2} \mathrm{NiO}_{5} \mathrm{P}_{2}, \mathrm{C} 34.27, \mathrm{H} 4.15$, N 4.44\%.

Synthesis of [(N2P2) Ni(MeCN $\left.)_{2}\right]\left(\mathrm{SbF}_{6}\right)_{2}(2)$. The complex was prepared under $\mathrm{N}_{2}$. A solution of $\mathrm{AgSbF}_{6}(76 \mathrm{mg}, 0.221 \mathrm{mmol})$ was added to a solution of (N2P2)NiBr2 (68 mg, $0.111 \mathrm{mmol})$ in MeCN. After stirring for $15 \mathrm{~min}$, the mixture turned green and the solution was filtered and concentrated for recrystallization by ether diffusion. Green crystals formed, and the supernatant was removed. The resulting solid was washed with ether and dried in vacuo. The product [(N2P2)Ni(MeCN)2] $\left(\mathrm{SbF}_{6}\right)_{2}$ was isolated as a green solid. Yield: $66 \mathrm{mg}, 61 \%$. Elemental analysis: found, C 26.27, H $2.93 \mathrm{~N}$ $5.70 \%$; calculated $\mathrm{C}_{22} \mathrm{H}_{30} \mathrm{~F}_{12} \mathrm{~N}_{4} \mathrm{NiO}_{4} \mathrm{P}_{\mathrm{S}} \mathrm{Sb}_{2}, \mathrm{C} 26.25, \mathrm{H} 3.00, \mathrm{~N}$ $5.57 \%$.

Synthesis of [(N2P2)Ni(OTf $\left.)_{2}\right]$ (3). The complex was prepared under $\mathrm{N}_{2}$. Into a solution of (N2P2) $\mathrm{NiBr}_{2}(15 \mathrm{mg}, 0.0 .024 \mathrm{mmol})$ in $\mathrm{MeCN}$, AgOTf (13 mg, $0.048 \mathrm{mmol}$ ) was added. After stirring for 1 hour, the solution turns green and was filtered and concentrated. Toluene was layered on the solution and slow evacuation resulted in purple crystals. The crystals were washed with ether, and the isolated crystals were dried in vacuo. The product [(N2P2)Ni(OTf)2] was isolated as a purple solid. Yield: $17 \mathrm{mg}, 90 \%$.

Synthesis of $[(\mathrm{N} 2 \mathrm{P} 2) \mathrm{Ni}(\mathrm{CNtBu})]\left(\mathrm{SbF}_{6}\right)_{2}(4)$. The complex was prepared under $\mathrm{N}_{2}$. Into a solution of [(N2P2)Ni(MeCN) $)_{2}\left(\mathrm{SbF}_{6}\right)_{2}(42 \mathrm{mg}, 0.0435 \mathrm{mmol})$ in $\mathrm{MeCN}$, tBuNC $(4.9 \mu \mathrm{L}, 0.0435 \mathrm{mmol})$ was added. After stirring for 30 min, the solution turns a darker green and was filtered. Ether was added to the solution to crash out pink/purple crystals. The crystals were washed with ether, and the isolated crystals were dried in vacuo. The product $[(\mathrm{N} 2 \mathrm{P} 2) \mathrm{Ni}(\mathrm{CNtBu})]\left(\mathrm{SbF}_{6}\right)_{2}$ was isolated as a pink solid. Yield: $33.6 \mathrm{mg}, 77 \%$. ${ }^{1} \mathrm{H}$ NMR (CD $\left.{ }_{3} \mathrm{CN}, 300 \mathrm{MHz}\right), \delta(\mathrm{ppm}): 1.87$ (s, 18H, tBu), 7.20 (d, 8H, Py $\mathrm{H}_{\text {meta }}$ ), 8.14 (br, $2 \mathrm{H}, \mathrm{Py} \mathrm{H}_{\text {para }}$ ). Elemental analysis: found, $\mathrm{C}$ 27.09, H 2.95 N 4.21\%; calculated $\mathrm{C}_{23} \mathrm{H}_{35} \mathrm{~F}_{12} \mathrm{~N}_{3} \mathrm{NiO}_{5} \mathrm{P}_{2} \mathrm{Sb}_{2}$, C 26.93, H 3.44, N 4.10\%.

EPR studies of the $\mathrm{Ni}^{I}$ species. An EPR tube was charged with a solution of the Ni complex in 1:3 MeCN/PrCN (v:v) and immersed into liquid nitrogen. Another solution containing 1 equiv of chemical reductant in the same solvent mixture was quickly added, mixed, and frozen in the EPR tube. An initial EPR spectrum was taken at $77 \mathrm{~K}$. The sample was then carefully warmed up for 10-30 s to allow the two layers to further mix, quickly refrozen, and the EPR spectrum was recorded. The warming up step was repeated if necessary.

Low temperature $U V$-vis studies of the $\left[(\mathrm{N} 2 \mathrm{P} 2) \mathrm{Ni}^{\mathrm{I}}(\mathrm{CNtBu})\right]^{+}$ (5) complex. A $5 \mathrm{~mL}$ solution of $4(0.5 \mathrm{mM})$ in MeCN was prepared and UV-vis spectra were recorded initially only for $\mathbf{4}$, and monitored immediately after addition of 1 equiv of $\mathrm{CoCp}_{2}$ in order to observe $\mathbf{5}$ in solution.

$X$-ray structure determination. Crystals of appropriate dimensions were mounted on MiTeGen cryoloops in random orientations. Preliminary examination and data collection were performed using a Bruker Kappa Apex II or SMART Apex II Charge Coupled Device (CCD) Detector system single crystal XRay diffractometers equipped with an Oxford Cryostream LT device. All data were collected using graphite monochromated Mo K $\alpha$ radiation $(\lambda=0.71073 \AA$ ) from a fine focus sealed tube $\mathrm{X}$-Ray source. Preliminary unit cell constants were determined with a set of 36 narrow frame scans. Typical data sets consist of combinations of $\varpi$ and $\phi$ scan frames with typical scan width of $0.5^{\circ}$ and counting time of $15-30$ seconds/frame at a crystal to detector distance of $3.5-5.0 \mathrm{~cm}$. The collected frames were integrated using an orientation matrix determined from the narrow frame scans. Apex II and SAINT software packages ${ }^{45}$ were used for data collection and data integration. Analysis of the integrated data did not show any decay. Final cell constants were determined by global refinement of xyz centroids for the complete data set. The collected data were corrected for systematic errors using SADABS 45 based on the Laue symmetry using equivalent reflections. Crystal data and intensity data 
collection parameters as well as additional details of structure refinement are given in the SI. Structure solution and refinement were carried out using the SHELXTL-PLUS software package. ${ }^{46}$ The structure was solved by direct methods or Patterson method and refined successfully in the space groups listed below. Full matrix least-squares refinement was carried out by minimizing $\Sigma \mathrm{w}\left(\mathrm{F}_{0}^{2}-\mathrm{F}_{\mathrm{C}}^{2}\right)^{2}$. The non-hydrogen atoms were refined anisotropically to convergence.

\section{Results and Discussion}

\section{Synthesis and Structural Characterization of (N2P2)Ni} Complexes 1-4

The tetradentate diphosphonite pyridinophane ligand N2P2 was synthesized using modified procedures reported for noncyclic PNP pincer ligands. ${ }^{37,47-49}$ The (N2P2)NiII complexes 1-4 (Scheme 1) were synthesized in $60-90 \%$ yield by using common $\mathrm{Ni}^{\mathrm{II}}$ precursors and synthetic procedures. The complex (N2P2) $\mathrm{NiBr}_{2}$ (1) was obtained through reaction of $\mathrm{Ni}(\mathrm{DME}) \mathrm{Br}_{2}$ with 1 equiv $\mathrm{N} 2 \mathrm{P} 2$ in $\mathrm{CH}_{2} \mathrm{Cl}_{2}$ /pentane. The complex $\left[(\mathrm{N} 2 \mathrm{P} 2) \mathrm{Ni}\left(\mathrm{MeCN}_{2}\right]\left(\mathrm{SbF}_{6}\right)_{2}\right.$ (2) was conveniently synthesized by bromide abstraction by 2 equiv. of $\mathrm{AgSbF}_{6}$ from (N2P2)NiBr2 (1). The complex [(N2P2)Ni(OTf)2] (3) could not be synthesized by reacting $\mathrm{Ni}(\mathrm{OTf})_{2}$ with $\mathrm{N} 2 \mathrm{P} 2$, but instead was prepared through bromide abstraction by 2 equiv of AgOTf from $\mathbf{1}$. The product obtained by the reaction of $\mathbf{2}$ with 1 equiv of tBuNC in MeCNe was found to be the monoisocyanide complex [(N2P2) Ni(CNtBu)] $\left(\mathrm{SbF}_{6}\right)_{2}(4)$ in the solid state, according to single crystal X-ray analysis (Figure 1 ). To our surprise, the addition of 2 equiv tBuNC could not produce the bisisocyanide complex, and instead resulted in the decomposition of the complex. All complexes were isolated and purified by recrystallization and characterized by spectroscopic methods. The effective magnetic moments were measured in $\mathrm{CDCl}_{3}$ for $\mathbf{1}$ and $\mathrm{CD}_{3} \mathrm{CN}$ for $\mathbf{2}$ and $\mathbf{3}$ at RT and their values were consistent with the expected value for a high-spin octahedral complex. Complexes $\mathbf{1}$, 2 , and 3 had a magnetic moment of $2.4 \mu_{\mathrm{B}}, 3.0 \mu_{\mathrm{B}}$, and $2.3 \mu_{\mathrm{B}}$, respectively. Complexes $\mathbf{1}$ and $\mathbf{2}$ were further characterized by elemental analysis.

X-ray quality crystals for complexes 1-4 were obtained by slow diffusion of pentane into concentrated solution of $\mathrm{CH}_{2} \mathrm{Cl}_{2}$ for 1 and slow diffusion of $\mathrm{Et}_{2} \mathrm{O}$ into concentrated solutions in $\mathrm{MeCN}$ for 2-4. The ORTEP plots and selected metrical parameters are given in Figure 1. The X-ray crystal structure of $\mathbf{1}, \mathbf{2}$, and 3 reveal a distorted octahedral coordination at the $\mathrm{Ni}(\mathrm{II})$

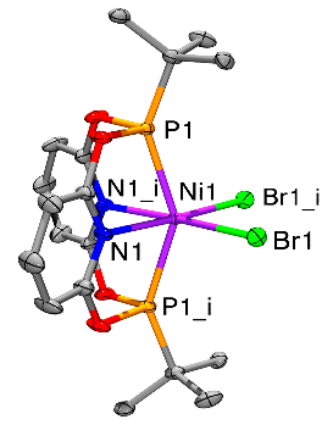

1

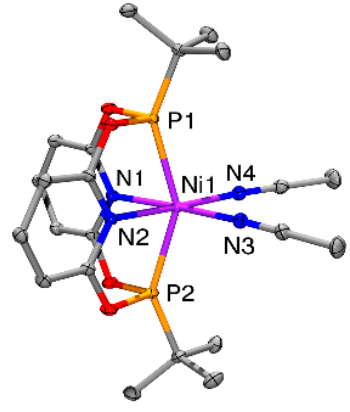

2 center, with the axial Ni-P bonds tilted toward the ligand (P-Ni$\left.\mathrm{P}=148.9^{\circ}, 1 ; 150.46^{\circ}, 2 ; 152.04^{\circ}, 3\right)$. The average $\mathrm{Ni}-\mathrm{N}$ bond lengths for 1,2 , and 3 are 2.102, 2.080, and 2.054 $\AA$, respectively. This trend of decreasing metal-ligand bond length is due to the decreasing strength of trans influence of the ligands ( $\mathrm{Br}$ $>$ MeCN > OTf). The X-ray crystal structure of 4 revealed a distorted trigonal bipyramidal coordination. Similar to 1, 2, and 3, the axial Ni-P bonds tilt toward the ligand $\left(\mathrm{P}-\mathrm{Ni}-\mathrm{P}=157.8^{\circ}\right)$, albeit to a lesser extent given the reduced coordination number that leads to less steric repulsion.

\section{Electrochemical Studies}

The electrochemical properties of (N2P2)NiII complexes were studied by cyclic voltammetry (CV, Table 1 and Figures S3-S6). ${ }^{50}$ The CVs of 1-4 in $0.1 \mathrm{M} \mathrm{Bu}_{4} \mathrm{NClO}_{4} / \mathrm{MeCN}$ all show quasi-reversible redox waves for $\mathrm{Ni}^{\mathrm{i} / \mathrm{II}}$ (Table 1). Interestingly, $\mathrm{Ni}^{\mathrm{II} / \mathrm{III}}$ oxidation redox waves, which are absent in complexes 2 4, are observed for $\mathbf{1}$ at $E_{1 / 2}$ of $0.46 \mathrm{~V}$ and $0.795 \mathrm{~V}$, respectively (Figure S3).

Table 1. Cyclic Voltammetry (CV) Data for (N2P2)Ni Complexes

\begin{tabular}{ccccc}
\hline Complex & $\mathbf{1}$ & $\mathbf{2}$ & $\mathbf{3}$ & $\mathbf{4}$ \\
\hline $\mathrm{E}^{\mathrm{I} / \mathrm{II}} 1 / 2, \mathrm{Va}$ & -0.875 & -0.750 & -1.170 & -0.630 \\
$\Delta \mathrm{E}, \mathrm{mV}$ & 150 & 220 & 140 & 220 \\
$\mathrm{E}_{\mathrm{pa}}, \mathrm{V}$ & -0.800 & -0.640 & -1.100 & -0.520 \\
\hline
\end{tabular}

${ }^{a} \mathrm{E}^{1 / \mathrm{II}} 1 / 2, \mathrm{~V}\left(\Delta \mathrm{E}_{\mathrm{p}}, \mathrm{mV}\right) ; \mathrm{E}_{\mathrm{pa}}$ values reported vs $\mathrm{Fc}$ at room temperature, $100 \mathrm{mV} / \mathrm{s}$ scan rate.

\section{Electron paramagnetic resonance (EPR) studies}

The one-electron reduction of complex 3 was carried out by chemical reduction with 1 equiv of cobaltocene $\left(\mathrm{CoCp}_{2}\right)$ to generate the $\mathrm{Ni}^{\mathrm{I}}$ species [(N2P2) $\left.\mathrm{Ni}^{\mathrm{I}}(\mathrm{OTf})(\mathrm{MeCN})\right]$ (5). The EPR spectrum $(77 \mathrm{~K}, 1: 3 \mathrm{MeCN}$ :PrCN glass) of 5 reveals a pdeudoaxial signal corresponding to a $\mathrm{Ni}^{\mathrm{I}}, \mathrm{d}^{9}$ metal center with a $\mathrm{d}_{\mathrm{z}}{ }^{2}$ ground state and gave $=2.05940$ (Figure 2). The EPR spectrum revealed superhyperfine coupling $\left(A_{2 P}=11-100 \mathrm{G}, I=1 / 2\right)$ to the two axial $\mathrm{P}$ donors, and also to the single equatorial $\mathrm{N}$ donor $\left(A_{1 N}=10-33 \mathrm{G}, \mathrm{I}=1\right)$. It is expected that in solution the triflate anions can be replaced by MeCN solvent molecules, which will

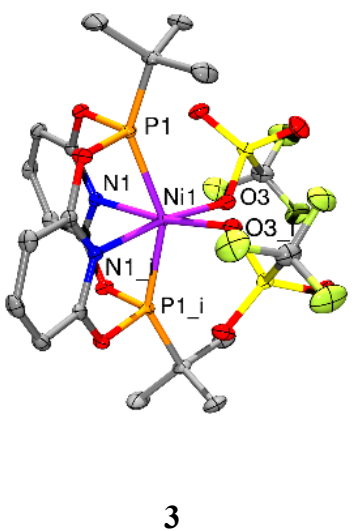

Figure 1. ORTEP representations (50\% thermal ellipsoids) of the X-ray crystal structures of 1-4. Selected bond distances $(\AA)$ : 1, Ni1-Br1 = 2.4869(5), Ni1-Br1_i = 2.4871(5), Ni1-N1 = 2.102(2), Ni1-N1_i = 2.102(2), Ni1-P1 = 2.3138(8), Ni1-P1_i = 2.3137(8); 2 , Ni1-N3 = 2.0374(13), Ni1-N4 = 2.0544(14), Ni1-N1 = 2.0881(12), Ni1-N2 = 2.0717(12), Ni1-P1 = 2.3271(4), Ni1$\mathrm{P} 2=2.3301(4) ; 3, \mathrm{Ni1}-\mathrm{O} 3=2.0429(14), \mathrm{Ni1}-03 \_\mathrm{i}=2.0428(14), \mathrm{Ni1}-\mathrm{N} 1=\mathrm{Ni1}=\mathrm{N} 1 \_\mathrm{i}=2.0535(16), \mathrm{Ni1}-\mathrm{P} 1=\mathrm{Ni1}-\mathrm{P} 1 \_\mathrm{i}=$ $2.3140(5) ; 4, \mathrm{Ni1}-\mathrm{C}(10)=1.80(2), \mathrm{Ni1}-\mathrm{N} 1$ = Ni1-N1_i = 1.963(9), Ni1-P1 = Ni1-P1_i = 2.145(3). 
provide the $\mathrm{N}$ atom that can undergo superhyperfine coupling to the $\mathrm{Ni}^{\mathrm{I}}$ center. Thus, we propose the formation of a 5- or 4coordinate $[(\mathrm{N} 2 \mathrm{P} 2) \mathrm{Ni}(\mathrm{MeCN})]^{+}$species in solution, with the $\mathrm{N} 2 \mathrm{P} 2$ ligand bound in $\mathrm{a} \mathrm{K}^{3}$ or $\mathrm{\kappa}^{4}$ conformation.

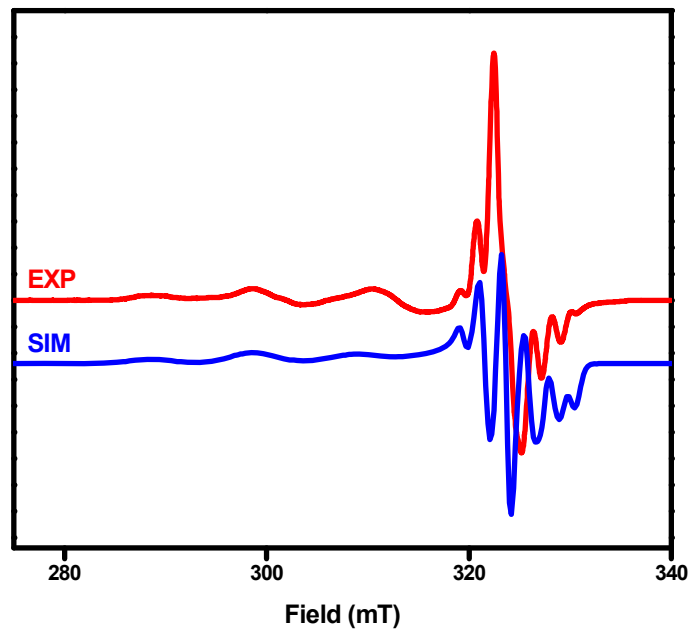

Figure 2. EPR spectrum (red line) of [(N2P2) $\left.\mathrm{Ni}^{1}(\mathrm{OTf})(\mathrm{MeCN})\right]$ (5) in 3:1 PrCN:MeCN glass at $77 \mathrm{~K}$, and the simulated EPR spectrum (blue line) using the following parameters: $\mathrm{g}_{\mathrm{x}}=2.007$ $\left(\mathrm{A}_{2 \mathrm{P}}=21 \mathrm{G} ; \mathrm{A}_{1 \mathrm{~N}}=22 \mathrm{G}\right), \mathrm{g}_{\mathrm{y}}=1.994\left(\mathrm{~A}_{2 \mathrm{P}}=11 \mathrm{G} ; \mathrm{A}_{1 \mathrm{~N}}=33 \mathrm{G}\right), \mathrm{g}_{\mathrm{z}}=$ $2.177\left(\mathrm{~A}_{2 \mathrm{P}}=100 \mathrm{G} ; \mathrm{A}_{1 \mathrm{~N}}=10 \mathrm{G}\right)$. Frequency: $9096.337 \mathrm{MHz}$.

One-electron reduction of complex $\mathbf{4}$ was also carried out by chemical reduction with 1 equiv $\mathrm{CoCp}_{2}$ to generate the $\mathrm{Ni}^{\mathrm{I}}$ species $\left[(\mathrm{N} 2 \mathrm{P} 2) \mathrm{Ni}^{\mathrm{I}}(\mathrm{CNtBu})\right]^{+}(\mathbf{6})$. The EPR spectrum $(77 \mathrm{~K}, 1: 3$ MeCN:PrCN glass) of 6 reveals a rhombic signal corresponding to a $\mathrm{Ni}^{\mathrm{I}}, \mathrm{d}^{9}$ metal center with $\mathrm{a} \mathrm{d}_{\mathrm{z}}{ }^{2}$ ground state and $\mathrm{g}_{\mathrm{ave}}=2.0585$ (Figure 3a). The EPR spectrum revealed strong superhyperfine coupling $\left(A_{2 P}=182-199 \mathrm{G}, I=1 / 2\right)$ to the two axial P donors, suggesting an appreciable delocalization of the unpaired electron onto the phosphorous atoms of the N2P2 ligand, and as supported by the DFT-calculated spin density plot (Figure 3c). Similarly, large phosphorous coupling ranging from $18-31 \mathrm{G}$ has been reported for nickel complexes stabilized by PCP pincer ligand, where Kozhanov et. al. speculates that the phosphorous coupling reflects the amount of contribution from a group metal-pincer orbital to the orbital containing the unpaired electron. ${ }^{51,52}$ Therefore, the strong accepting tBuNC ligand leads to a greater superhyperfine coupling constant vs. the OTf or MeCN ligands in 5. The stronger interaction with the $\mathrm{P}$ atoms could also lead to a preferred trigonal bipyramidal geometry for this $\mathrm{Ni}^{\mathrm{I}}$ species.

The $\mathrm{Ni}^{\mathrm{I}}$ EPR can be observed for up to 1 hour at $\mathrm{RT}$, although but at $45 \mathrm{~min}$ the signal has decreased significantly (>80\%). A room temperature EPR (298 K, 1:3 MeCN:PrCN glass) was also prepared where the sample prepared at low temperature was quickly thawed to room temperature and was immediately put into the instrument. The room temperature EPR also revealed strong superhyperfine coupling $\left(\mathrm{A}_{2 \mathrm{P}}=185.8 \mathrm{G}\right)$ to the two $\mathrm{P}$ donors with $g=2.06992$ (Figure $3 \mathrm{~b}$ ). a)

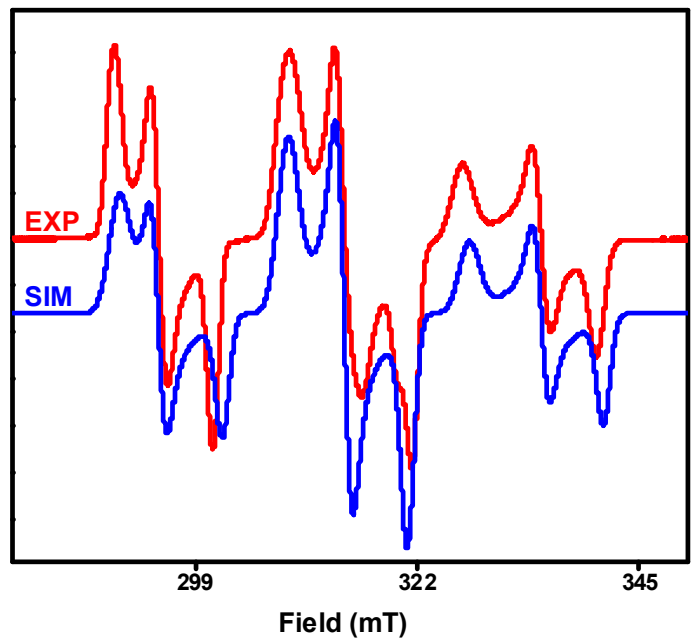

b)

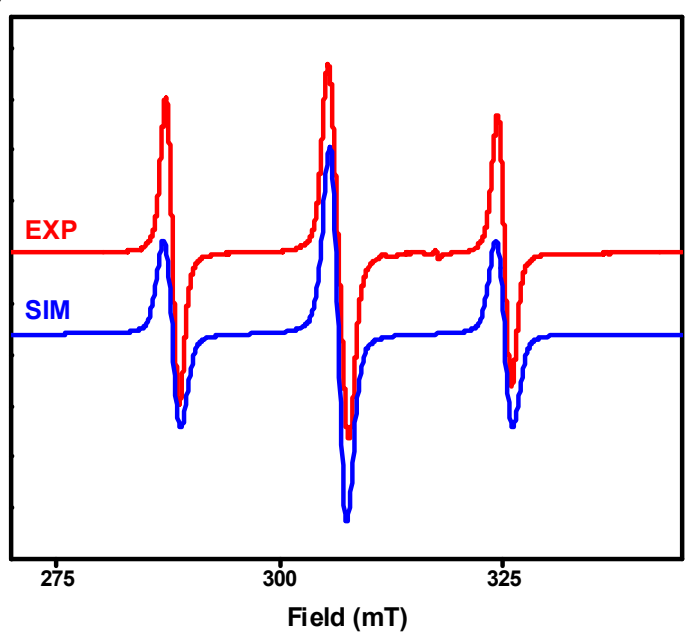

c)

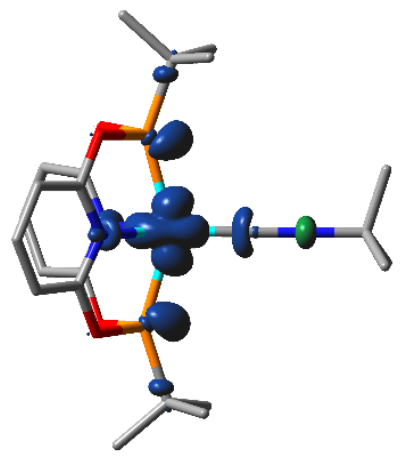

Figure 3. a) EPR spectrum (red line) of [(N2P2)Ni(CNtBu)](SbF6) (6) in 3:1 PrCN:MeCN glass, $77 \mathrm{~K}$, and the simulated EPR spectrum (blue line) using the following parameters: $g_{\mathrm{x}}=2.098\left(\mathrm{~A}_{2 \mathrm{P}}=182 \mathrm{G}\right), \mathrm{g}_{\mathrm{y}}=2.060\left(\mathrm{~A}_{2 \mathrm{P}}=199 \mathrm{G}\right)$, $\mathrm{g}_{\mathrm{z}}=2.017\left(\mathrm{~A}_{2 \mathrm{P}}=198 \mathrm{G}\right)$. Frequency: $\left.9092.747 \mathrm{MHz} . \mathrm{b}\right) \mathrm{EPR}$ spectrum (red line) of [(N2P2) Ni(CNtBu)]($\left(\mathrm{SbF}_{6}\right)(6)$ in $3: 1$ PrCN:MeCN glass, room temperature, and the simulated EPR spectrum (blue line) using the following parameters: $g_{a v e}=$ $2.070\left(\mathrm{~A}_{2 \mathrm{P}}=186 \mathrm{G}\right)$. Frequency: $8879.542 \mathrm{MHz}$. c) DFTcalculated spin density for $\mathbf{6}$, shown as a 0.03 isodensity contour plot. 


\section{Isolation of the (N2P2) $\mathrm{Ni}^{\mathrm{I}}$ complex 6}

The surprising stability of $\mathbf{6}$ allowed for its isolation. Into a solution of 4, 1 equiv of $\mathrm{CoCp} 2$ was added at $-70{ }^{\circ} \mathrm{C}$ and the solution was stirred for $30 \mathrm{~min}$ as its color changed from pink to purple. The dark purple solution was filtered, and a dark purple solid was precipitated using diethyl ether. The resulting solid was dried in vacuo, and the product of a $\mathrm{Ni}^{\mathrm{I}}$ species was confirmed via EPR. While X-ray quality crystals of $\mathbf{6}$ could not be obtained despite several attempts, the complex was further analyzed by X-ray photoelectron spectroscopy (XPS). The resulting XPS spectrum shows a decrease in the Ni $2 \mathrm{p}_{3 / 2}$ and $2 \mathrm{p}_{1 / 2}$ binding energies of $\sim 1.39 \mathrm{eV}$ between 4 and $\mathbf{6}$ and is consistent with the presence of a more reduced Ni center in 6 vs. 4 (Figure 4).

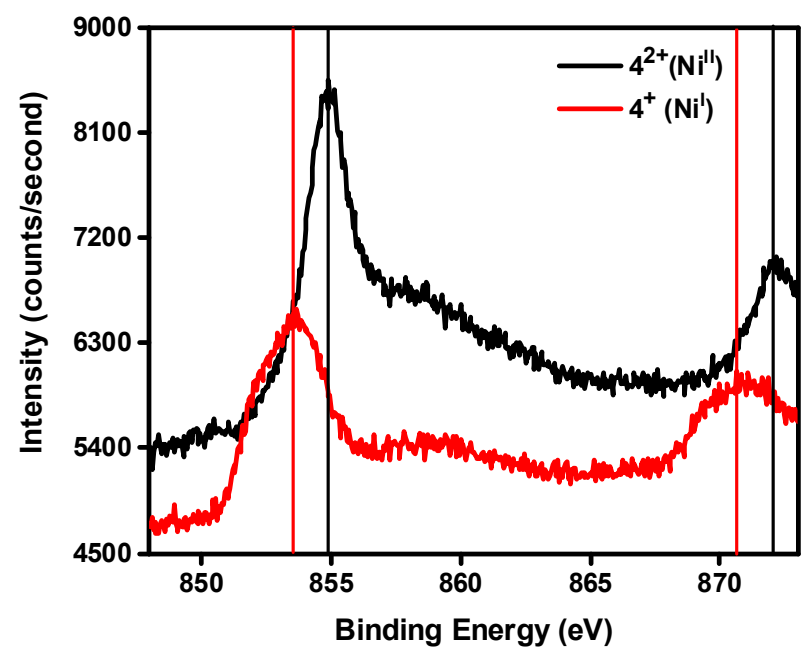

Figure 4. X-ray photoelectron spectra of the Ni binding energy region for complexes 4 (black line) and 6 (red line). Selected binding energies (eV), 4: 2 $\mathrm{p}_{3 / 2}, 854.88 ; 2 \mathrm{p}_{1 / 2}, 872.18 ; 6$ : $2 \mathrm{p}_{3 / 2}$, 853.66; $2 \mathrm{p}_{1 / 2}, 870.94$.

To further probe the formation of a $\mathrm{Ni}^{\mathrm{I}}$ species, the reduction reaction of 4 to yield $\mathbf{6}$ was carried out in MeCN at low temperature and monitored by UV-vis spectroscopy. The spectrum reveals two bands at 543 and $468 \mathrm{~nm}$ that appear after the addition of $\mathrm{CoCp}_{2}$ at $-45^{\circ} \mathrm{C}$, followed by their decay during the next few minutes as the cell was warmed to room temperature (Figure 5a). Time dependent density functional theory (TD-DFT) calculated UV-vis spectrum and transitions of $\mathbf{6}$ show similar transitions to the experimental spectrum (Figure 5b) providing support for the proposed trigonal bipyramidal geometry of $\mathbf{6}$ with N2P2 ligand binding in a $\kappa^{4}$ conformation.

Further insight into the electronic properties of 6 was obtained by density functional theory (DFT) calculations. The geometry optimized structure of 6 reveals a $\mathrm{Ni}^{\mathrm{I}}$ center in a trigonal bipyramidal geometry and the unpaired electron in a $\mathrm{d}_{\mathrm{z}}{ }^{2}$ ground state (Figure 3c), in line with the observed EPR spectrum.
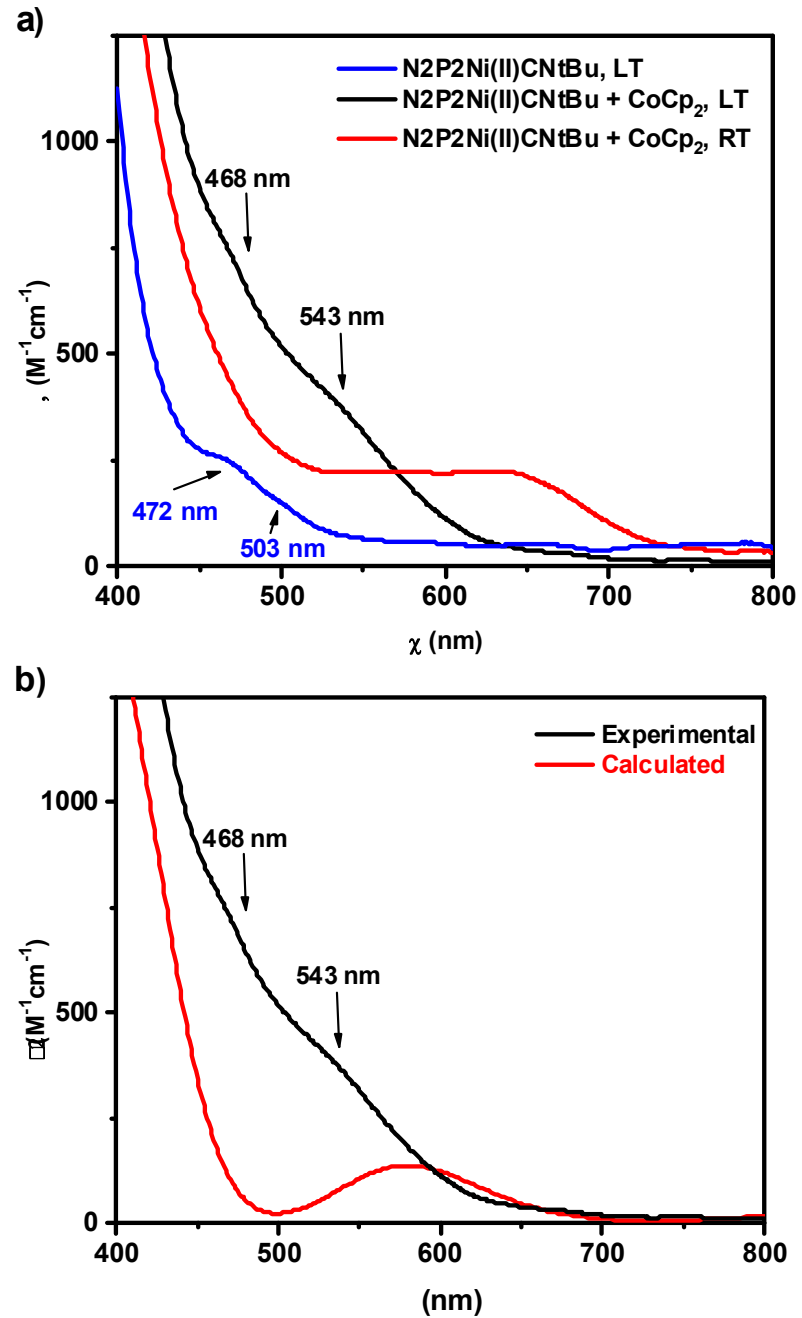

Figure 5. (a) In situ UV-vis spectra of the reduction of $4(0.5$ $\mathrm{mM}$, black line) with 1 equiv. of $\mathrm{CoCp}_{2}$ in $\mathrm{MeCN}$ at $-45^{\circ} \mathrm{C}$ : (blue line) initial spectrum before adding $\mathrm{CoCp}_{2}$ at $-45{ }^{\circ} \mathrm{C}$; (red line) spectrum at room temperature after adding $\mathrm{CoCp}_{2}$. (b) Experimental and normalized calculated TD-DFT UV-vis spectrum of 6.

\section{Kumada Cross-Coupling Reactivity}

Since the CV Studies have revealed that 1 can be oxidized and reduced in situ to the $\mathrm{Ni}^{\mathrm{III}}$ and $\mathrm{Ni}^{\mathrm{I}}$ species, respectively (Figure S3), ${ }^{50}$ we proposed that $\mathbf{1}$ may be an active catalyst for the Kumada cross-coupling of aryl iodides with aryl or alkyl Grignard reagents. Excitingly, the reaction of iodotoluene with phenylmagnesium bromide or 1-hexylmagnesium bromide affords the corresponding coupled products in 99\% and 95\% unoptimized yields, respectively (Scheme 2). By contrast, a lower yield of $17 \%$ was observed for the reaction of octyl-iodide with hexylMgBr. ${ }^{50}$ Similar results were observed recently using (MeN4)NiMe 2 complex, ${ }^{36}$ but we were pleasantly surprised to see complex 1 having a much higher yield of 95\% for the crosscoupling reaction with hexylMgBr, in contrast to the $60 \%$ yield observed by the (MeN4)NiMe2 complex. Further mechanistic studies are in progress to further probe the catalytic reactivity of these (N2P2)Ni complexes. 
Scheme 2. Kumada Cross-Coupling Reactions Catalyzed by $1^{a}$

\begin{tabular}{|c|c|c|c|}
\hline $\mathrm{R}-\mathrm{X}$ & $+\mathrm{R}^{\prime}-\mathrm{MgBr}$ & $\frac{\%(\mathrm{~N} 2 \mathrm{P} 2) \mathrm{NiBr}_{2}}{\mathrm{THF}, \mathrm{RT}}$ & R-R' \\
\hline $\mathrm{R}-\mathrm{X}$ & $\mathrm{R}^{\prime} \mathrm{MgX}$ & Reaction time, $\mathrm{h}$ & Yield, \% \\
\hline p-tolyl-I & phenylMgBr & 1 & 99 \\
\hline p-tolyl-I & hexylMgBr & 1 & 95 \\
\hline octyl-I & hexylMgBr & 1 & 17 \\
\hline
\end{tabular}

aYields were determined using GC-FID with decane as the internal standard; no coupled products were observed in the absence of 1 .

\section{Conclusion}

In conclusion, herein we have reported the use of a novel Nand $\mathrm{P}$ - donor ligand, $\mathrm{P}, \mathrm{P}^{\prime}$-ditertbutyl-2,11-diphosphonito[3.3] $(2,6)$ pyridinophane (N2P2) to stabilize various Ni complexes and study their electronic properties and reactivity. Interestingly, a $\mathrm{Ni}^{\mathrm{I}}$ complex [(N2P2) Ni(CNtBu)]( $\left.\mathrm{SbF}_{6}\right)$ complex was isolated and characterized by EPR and XPS. In addition, the (N2P2) NiBr2 complex was shown to be a competent catalyst in Kumada cross-coupling reactions. Overall, the newly developed N2P2 ligand provides $\mathrm{P}$ donor atoms to interact with the $\mathrm{Ni}$ centers and thus stabilize low-valent $\mathrm{Ni}$ species, in contrast to the all-N donor N4-type ligands. Thus, the redox reactivity of the various (N2P2) Ni complexes is expected to be far-reaching and is currently being further explored for other catalytic and electrocatalytic applications.

\section{ASSOCIATED CONTENT}

Supporting Information Available: Figures, tables, and CIF files giving cyclic voltammograms, ESI-MS spectra, EPR simulation details, 1H NMR spectra, and X-ray crystallographic data, and computational details. This material is available free of charge via the Internet at http://pubs.acs.org.

\section{AUTHOR INFORMATION}

\section{Corresponding Author}

*E-mail:mirica@illinois.edu

ORCID: 0000-0003-0584-9508

\section{ACKNOWLEDGMENTS}

We thank the Department of Energy's BES Catalysis Science Program (DE-SC0006862) for financial support.

\section{REFERENCES}

1. Devasagayaraj, A.; Studemann, T.; Knochel, P. A new nickelcatalyzed cross-coupling reaction between $\operatorname{sp(3)}$ carbon centers Angew. Chem., Int. Ed. 1995, 34, 2723.

2. Netherton, M. R.; Fu, G. C. Nickel-catalyzed cross-couplings of unactivated alkyl halides and pseudohalides with organometallic compounds Adv. Synth. Catal. 2004, 346, 1525.

3. Frisch, A. C.; Beller, M. Catalysts for cross-coupling reactions with non-activated alkyl halides Angew. Chem., Int. Ed. 2005, 44,674 .
4. Terao, J.; Kambe, N. Cross-Coupling Reaction of Alkyl Halides with Grignard Reagents Catalyzed by Ni, Pd, or $\mathrm{Cu}$ Complexes with pi-Carbon Ligand(s) Acc. Chem. Res. 2008, 41, 1545.

5. Glorius, F. Asymmetric Cross-Coupling of Non-Activated Secondary Alkyl Halides Angew. Chem., Int. Ed. 2008, 47, 8347.

6. Rudolph, A.; Lautens, M. Secondary Alkyl Halides in Transition-Metal-Catalyzed Cross-Coupling Reactions Angew. Chem., Int. Ed. 2009, 48, 2656.

7. Phapale, V. B.; Cardenas, D. J. Nickel-catalysed Negishi crosscoupling reactions: scope and mechanisms Chem. Soc. Rev. 2009, 38, 1598.

8. $\mathrm{Hu}, \mathrm{X}$. Nickel-catalyzed cross coupling of non-activated alkyl halides: a mechanistic perspective Chem. Sci. 2011, 2, 1867.

9. Knochel, P.; Thaler, T.; Diene, C. Pd-, Ni-, Fe-, and Co-Catalyzed Cross-Couplings Using Functionalized $\mathrm{Zn-}$, Mg-, Fe-, and InOrganometallics Isr. J. Chem. 2012, 50, 547.

10. Tasker, S. Z.; Standley, E. A.; Jamison, T. F. Recent advances in homogeneous nickel catalysis Nature 2014, 509, 299.

11. Tsou, T. T.; Kochi, J. K. Reductive Coupling of Organometals Induced by Oxidation - Detection of Metastable Paramagnetic Intermediates J. Am. Chem. Soc. 1978, 100, 1634.

12. Tsou, T. T.; Kochi, J. K. Mechanism of biaryl synthesis with nickel complexes J. Am. Chem. Soc. 1979, 101, 7547.

13. Amatore, C.; Jutand, A. Rates and mechanism of biphenyl synthesis catalyzed by electrogenerated coordinatively unsaturated nickel complexes Organometallics 1988, 7, 2203.

14. Matsunaga, P. T.; Hillhouse, G. L.; Rheingold, A. L. Oxygenatom transfer from nitrous oxide to a nickel metallacycle synthesis, structure, and reactions of $(2,2$ 'bipyridine) Ni(OCH2CH2CH2CH2) J. Am. Chem. Soc. 1993, 115, 2075.

15. Koo, K. M.; Hillhouse, G. L.; Rheingold, A. L. Oxygen-Atom Transfer from Nitrous-Oxide to an Organonickel(Ii) Phosphine Complex - Syntheses and Reactions of New Nickel(Ii) Aryloxides and the Crystal-Structure of (Me(2)PCH 2CH2PMe2)Ni(O-O-C6H4CMe2CH2) Organometallics 1995 , 14,456 .

16. Lin, B. L.; Clough, C. R.; Hillhouse, G. L. Interactions of aziridines with nickel complexes: Oxidative-addition and reductive-elimination reactions that break and make C-N bonds J. Am. Chem. Soc. 2002, 124, 2890.

17. Jones, G. D.; McFarland, C.; Anderson, T. J.; Vicic, D. A. Analysis of key steps in the catalytic cross-coupling of alkyl electrophiles under Negishi-like conditions Chem. Comm. 2005, 4211.

18. Klein, A.; Budnikova, Y. H.; Sinyashin, O. G. Electron transfer in organonickel complexes of $\alpha$-diimines: Versatile redox catalysts for $\mathrm{C}-\mathrm{C}$ or $\mathrm{C}-\mathrm{P}$ coupling reactions - A review J. Organomet. Chem. 2007, 692, 3156.

19. Iluc, V. M.; Miller, A. J. M.; Anderson, J. S.; Monreal, M. J.; Mehn, M. P.; Hillhouse, G. L. Synthesis and Characterization of ThreeCoordinate Ni(III)-Imide Complexes J. Am. Chem. Soc. 2011, 133, 13055.

20. Yu, S.; Dudkina, Y.; Wang, H.; Kholin, K. V.; Kadirov, M. K.; Budnikova, Y. H.; Vicic, D. A. Accessing perfluoroalkyl nickel(II), (III), and (IV) complexes bearing a readily attached [C4F8] ligand Dalton Trans. 2015, 44, 19443.

21. Mohadjer Beromi, M.; Banerjee, G.; Brudvig, G. W.; Hazari, N.; Mercado, B. Q. Nickel(I) Aryl Species: Synthesis, Properties, and Catalytic Activity ACS Catal. 2018, 8, 2526.

22. Diccianni, J. B.; Diao, T. Mechanisms of Nickel-Catalyzed CrossCoupling Reactions Trend Chem. 2019, 1, 830.

23. Diccianni, J. B.; Katigbak, J.; Hu, C.; Diao, T. Mechanistic Characterization of (Xantphos)Ni(I)-Mediated Alkyl Bromide Activation: Oxidative Addition, Electron Transfer, or HalogenAtom Abstraction J. Am. Chem. Soc. 2019, 141, 1788.

24. Diccianni, J.; Lin, Q.; Diao, T. Mechanisms of Nickel-Catalyzed Coupling Reactions and Applications in Alkene Functionalization Acc. Chem. Res. 2020, 53, 906. 
25. Somerville, R. J.; Odena, C.; Obst, M. F.; Hazari, N.; Hopmann, K. H.; Martin, R. Ni(I)-Alkyl Complexes Bearing Phenanthroline Ligands: Experimental Evidence for $\mathrm{CO} 2$ Insertion at $\mathrm{Ni}(\mathrm{I})$ Centers J. Am. Chem. Soc. 2020, 142, 10936.

26. Khusnutdinova, J. R.; Rath, N. P.; Mirica, L. M. Stable Mononuclear Organometallic Pd(III) Complexes and Their CC Bond Formation Reactivity J. Am. Chem. Soc. 2010, 132, 7303.

27. Khusnutdinova, J. R.; Rath, N. P.; Mirica, L. M. The Aerobic Oxidation of a Pd(II) Dimethyl Complex Leads to Selective Ethane Elimination from a Pd(III) Intermediate J. Am. Chem. Soc. 2012, 134, 2414.

28. Tang, F.; Zhang, Y.; Rath, N. P.; Mirica, L. M. Detection of Pd(III) and $\mathrm{Pd}(\mathrm{IV})$ Intermediates during the Aerobic Oxidative C-C Bond Formation from a $\mathrm{Pd}(\mathrm{II})$ Dimethyl Complex Organometallics 2012, 31, 6690 .

29. Tang, F.; Qu, F.; Khusnutdinova, J. R.; Rath, N. P.; Mirica, L. M. Structural and Reactivity Comparison of Analogous Organometallic Pd(III) and Pd(IV) Complexes Dalton Trans. 2012, 41, 14046.

30. Mirica, L. M.; Khusnutdinova, J. R. Structure and Electronic Properties of Pd(III) Complexes Coord. Chem. Rev. 2013, 257, 299.

31. Zheng, B.; Tang, F.; Luo, J.; Schultz, J. W.; Rath, N. P.; Mirica, L. M. Organometallic Nickel(III) Complexes Relevant to CrossCoupling and Carbon-Heteroatom Bond Formation Reactions J. Am. Chem. Soc. 2014, 136, 6499 .

32. Zhou, W.; Schultz, J. W.; Rath, N. P.; Mirica, L. M. Aromatic Methoxylation and Hydroxylation by Organometallic HighValent Nickel Complexes J. Am. Chem. Soc. 2015, 137, 7604.

33. Tang, F. Z.; Rath, N. P.; Mirica, L. M. Stable bis(trifluoromethyl)nickel(III) complexes Chem. Comm. 2015 $51,3113$.

34. Zhou, W.; Rath, N. P.; Mirica, L. M. Oxidatively-induced aromatic cyanation mediated by Ni(III) Dalton Trans. 2016 $45,8693$.

35. Zhou, W.; Zheng, S. A.; Schultz, J. W.; Rath, N. P.; Mirica, L. M. Aromatic Cyanoalkylation through Double C-H Activation Mediated by Ni(III) J. Am. Chem. Soc. 2016, 138, 5777.

36. Schultz, J. W.; Fuchigami, K.; Zheng, B.; Rath, N. P.; Mirica, L. M. Isolated Organometallic Nickel(III) and Nickel(IV) Complexes Relevant to Carbon-Carbon Bond Formation Reactions J. Am. Chem. Soc. 2016, 138, 12928.

37. Bernskoetter, W. H.; Hanson, S. K.; Buzak, S. K.; Davis, Z.; White, P. S.; Swartz, R.; Goldberg, K. I.; Brookhart, M. Investigations of Iridium-Mediated Reversible C-H Bond Cleavage: Characterization of a 16-Electron Iridium(III) Methyl Hydride Complex J. Am. Chem. Soc. 2009, 131, 8603.

38. Bernskoetter, W. H.; Schauer, C. K.; Goldberg, K. I.; Brookhart, M. Characterization of a Rhodium(I) sigma-Methane Complex in Solution Science 2009, 326, 553.

39. Salem, H.; Shimon, L. J. W.; Diskin-Posner, Y.; Leitus, G.; BenDavid, Y.; Milstein, D. Formation of Stable trans-Dihydride
Ruthenium(II) and 16-Electron Ruthenium(0) Complexes Based on Phosphinite PONOP Pincer Ligands. Reactivity toward Water and Electrophiles Organometallics 2009, 28, 4791.

40. Findlater, M.; Bernskoetter, W. H.; Brookhart, M. ProtonCatalyzed Hydrogenation of a d8 Ir(I) Complex Yields a trans Ir(III) Dihydride J. Am. Chem. Soc. 2010, 132, 4534.

41. Kundu, S.; Brennessel, W. W.; Jones, W. D. Synthesis and Reactivity of New Ni, Pd, and Pt 2,6-Bis(di-tertbutylphosphinito)pyridine Pincer Complexes Inor. Chem. 2011, 50, 9443 .

42. Boudier, A.; Breuil, P.-A. R.; Magna, L.; Olivier-Bourbigou, H.; Braunstein, P. Nickel(II) complexes with imino-imidazole chelating ligands bearing pendant donor groups (SR, OR, NR2, PR2) as precatalysts in ethylene oligomerization $J$. Organomet. Chem. 2012, 718, 31.

43. Evans, D. F. The determination of the paramagnetic susceptibility of substances in solution by nuclear magnetic resonance J. Chem. Soc. 1959, 2003.

44. De Buysser, K.; Herman, G. G.; Bruneel, E.; Hoste, S.; Van Driessche, I. Determination of the Number of Unpaired Electrons in Metal-Complexes. A Comparison Between the Evans' Method and Susceptometer Results Chem. Phys. 2005, 315, 286.

45. Bruker Analytical X-Ray, Madison, WI, 2010.

46. Sheldrick, G. A short history of SHELX Acta Cryst. Sec. A: Found. Cryst. 2008, 64, 112.

47. Hermann, D.; Gandelman, M.; Rozenberg, H.; Shimon, L. J. W.; Milstein, D. Synthesis, structure, and reactivity of new rhodium and iridium complexes, bearing a highly electrondonating PNP system. Iridium-mediated vinylic $\mathrm{C}-\mathrm{H}$ bond activation Organometallics 2002, 21, 812.

48. Rubio, M.; Suárez, A.; Vega, E.; Álvarez, E.; Díez, J.; Gamasa, M. P.; Pizzano, A. Synthesis and Structural Characterization of Pincer Pyridine Diphosphite Complexes of Rhodium and Iridium Eur. J. Inorg. Chem. 2012, 2012, 655.

49. Kundu, S.; Brennessel, W. W.; Jones, W. D. Synthesis and Reactivity of New Ni, Pd, and Pt 2,6-Bis(di-tertbutylphosphinito)pyridine Pincer Complexes Inor. Chem. 2011, 50, 9443.

50. See Supporting Information.

51. Kozhanov, K. A.; Bubnov, M. P.; Cherkasov, V. K.; Fukin, G. K.; Abakumov, G. A. EPR study of intramolecular dynamics in osemiquinonic nickel complexes with PCP-pincer ligand in solution Dalton Trans. 2004, 2957.

52. Nevodchikov, V. I.; Abakumov, G. A.; Cherkasov, V. K.; Razuvaev, G. A. ESR investigation of the substitution reactions in rhodium(I) complexes with spin-labeled ligands $J$. Organomet. Chem. 1981, 214, 119. 
Table of Contents Graphic

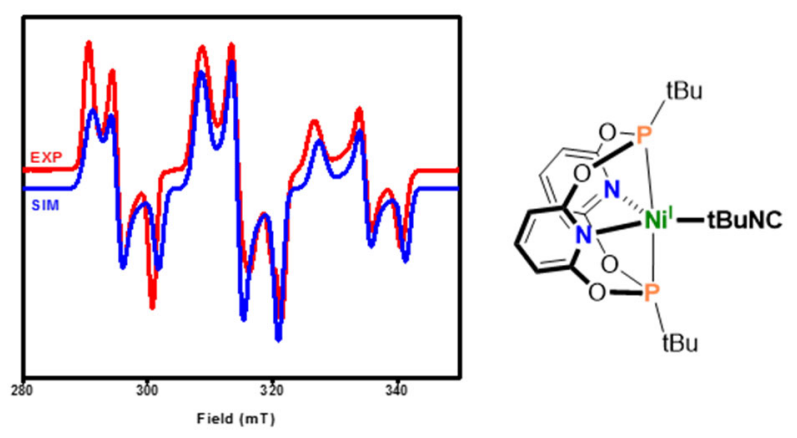

8 